\title{
Isolation of Mesenchymal Stem Cells from Wharton's Jelly in Comparison with Bone Marrow and Their Endothelial Differentiation
}

\author{
El Edel RH ${ }^{1}$, Khodeer $\mathrm{S}^{1}$, Noreldin RI ${ }^{1}, \mathrm{Ammar}{ }^{2}$ \\ ${ }^{I}$ Clinical pathology Department, Faculty of Medicine, Menoufia University, Egypt. \\ ${ }^{2}$ Gynaecology and obstetrics Department, Faculty of Medicine, Menoufia University, Egypt.
}

\begin{abstract}
:
Objective: Umbilical cord Wharton's jelly as source of mesenchymal stem cells (MSCs) can be easily obtained. In this study, MSCs were isolated from bone marrow and Wharton's jelly and induced to differentiate into endothelial-like cells.

Materials and Methods: MSCs were isolated and induced to differentiate into endothelial-like cells using vascular endothelial growth factor (VEGF). The endothelial differentiation was evaluated by morphological changes, flow-cytometric analysis of surface markers CD31, CD34, and detection of vascular endothelial cadherin (VE-cadherin) by immunocytochemical analysis. Proliferation curves were done for non-induced cells and the mean population doubling time was obtained.

Results: Umbilical cord Wharton's jelly (UC-MSCs) and bone marrow (BM-MSCs) induced with VEGF show spindle shape with no much morphology difference form MSCs. No significant difference between BM \& UC induced cells as regard to CD31 or CD34. Induced cells showed positive staining with VE-cadherin. The mean

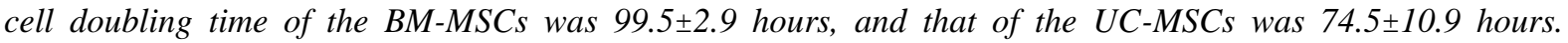
Conclusion: MSCs can be isolated from Wharton's jelly and UC can be easily obtained, representing a noncontroversial source of MSCs. UC-MSCs were induced to differentiate into endothelial-like cells, their endothelial differentiation potential was compareble to BM-MSCs.
\end{abstract}

Keywords: BM-MSCs, UC-MSCs.

\section{Introduction}

Adult bone marrow contains at least two types of stem cells; hematopoietic stem cells and mesenchymal stem cells (MSCs). Both cell types can be isolated from the mononuclear cell fraction of bone marrow aspirates [1]. MSCs have a large capacity for self-renewal while maintaining their multipotency and represent an attractive cell source for regeneration of damaged tissues in tissue engineering [2] and differentiate into different cells under suitable induction conditions [3]. Recent advances in stem cell technology have enabled researchers to derive endothelial or endothelial-like cells from stem cells [4].Endothelial cells (ECs) derived from stem cells could potentially lead to a variety of clinically relevant applications. These cells could be used in therapeutic strategies for the repair and revascularization of ischemic tissue in patients exhibiting vascular defects [5]. Human bone marrow-derived MSCs (BM-MSCs) can differentiate into endothelial-like cells [6]. However, BM harvesting is a highly invasive procedure to the donors. The multipotent differentiation potential, proliferation efficiency, and maximal lifespan of BM-MSCs decline with aging [7]. MSCs can also be isolated from alternative sources as umbilical cord Wharton's jelly (UC-MSCs) [8]. UC-MSCs are more primitive MSCs than those isolated from other tissue sources. [9]. UC-MSCs have also attracted great interest because of their immune modulatory properties. UC-MSCs are proposed as a possible versatile tool for regenerative medicine and immunotherapy [10]. In this study, UC-MSCs were induced to differentiate into endothelial-like cells and their endothelial differentiation potential was compared to the BM-MSCs. Growth curve analysis curves were done for non-induced MSCs from bone marrow and umbilical cord Wharton's jelly.

\section{Subjects And Methods}

The study involved 20 samples of bone marrow. Bone marrow samples were aseptically collected from patients who already have another indication for bone marrow examination, after obtaining their consent. The study also involved 10 pregnant females coming for delivery, 6 of them for umbilical cords collection and the other 4 for umbilical cord serum collection during the period from January 2015 to February 2016. Samples were aseptically collected from patients, after obtaining their consent.

Collection of blood samples for Preparation of serum: The collections were made prior to the expulsion of the placenta during normal vaginal delivery. Blood samples collected from patients were left at room 
temperature for clotting then centrifuged for $15 \mathrm{~min}$ at $3000 \mathrm{rpm}$, and then sera were collected in a single sterile falcon $50 \mathrm{ml}$ for heat inactivation by incubation at $56^{\circ} \mathrm{C}$ for $20 \mathrm{~min}$ then frozen for future use.

\section{Culture method for bone marrow samples:}

Mononuclear Cell (MNC) Separation was done under laminar flow area. The bone marrow aspirate was diluted with sterile PBS in the ratio of 1:1 and mixed well. The diluted blood was layered on top of lymphocyte separation medium. The tube was centrifuged for 20 minutes at $1800 \mathrm{rpm}$. The MNC fraction was collected and washed twice with sterile PBS. The MNC suspension was seeded at a concentration of million cells/ $\mathrm{cm} 2$ and allowed to adhere to tissue culture plastic flasks 25 (Corning ${ }^{\circledR}$ ) $\mathrm{cm} 2$, incubated in $5 \mathrm{ml}$ of the fresh complete nutrient medium which was constituted of the following: Low-glucose DMEM (DMEM-LG) with L-glutamine $(2 \mathrm{mmol} / \mathrm{L}), 10 \%$ FBS, Penicillin-streptomycin $(100 \mathrm{U} / \mathrm{ml}$ penicillin and $100 \mu \mathrm{g} / \mathrm{ml}$ streptomycin), Fungizone $(0.25 \mu \mathrm{g} / \mathrm{mL})$. The flasks were incubated in a horizontal position in a humidified incubator at $37 \mathrm{o} \mathrm{C}$ and 5\% CO2. Half medium was changed every 4 days for removal of non-adherent cells. At day 9 , when fibroblast-like cells reach $80-90 \%$ confluence, these cells were harvested by trypsinization.

\section{Culture method for umbilical cord}

Wharton's jelly was cut into small pieces of about $1.5-2.5 \mathrm{~mm}$. Tissue culture plastic flasks $25 \mathrm{~cm}^{2}$ (Corning®) were prepared for culture by adding 5ml DMEM-LG with L-glutamine, cord blood serum (100 $\mu \mathrm{g} / \mathrm{mL})$, Penicillin streptomycin $(100 \mathrm{U} / \mathrm{ml}$ penicillin and $100 \mu \mathrm{g} / \mathrm{ml}$ streptomycin $)(10 \mu \mathrm{g} / \mathrm{mL})$, Fungizone $(0.25$ $\mu \mathrm{g} / \mathrm{mL}$ Wharton's jelly pieces were divided and distributed on tissue culture plastic flasks, the amount was added in each flask to be covered completely with media. The flasks were incubated in a horizontal position in in a humidified incubator at $37 \mathrm{o} \mathrm{C}$ and $5 \% \mathrm{CO} 2$. At day 7, the tissue removed by changing the medium. The flasks were washed extensively twice with warm media, and the adherent cells (MSCs) were kept in culture and were fed with fresh complete nutrient medium (about 1 weeks later). These cells were kept until the outgrowth of fibroblast-like cells. At day 14, cells were examined microscopically to ensure $60-70 \%$ confluence, and then these cells were harvested by trypsinization.

Trypsinization: one to $3 \mathrm{ml}$ of trypsin-EDTA detachment solution was added to the flask. The closed flask was gently shaken and taped on the sides to completely immerse the cells. After complete detachment, DMEM containing $1 \%$ serum was added at the same volume as the volume of trypsin used. The cells were transferred to centrifuge $15 \mathrm{ml}$ falcon tube and centrifuged at $1800 \mathrm{rpm}$ for 10 minutes. The supernatant was removed and the cells were resuspended in complete media as a single cell suspension.

\section{Identification of MSCs:}

The harvested MSCs were identified by flow cytometric analysis of surface markers CD44, CD34 and CD31. One hundred $\mu \mathrm{l}$ of cell suspension was added to $10 \mu \mathrm{l}$ fluorochrome reagents which were conjugated with fluorescein isothiocyanate (FITC) or phycoerythrin (PE): CD44-PE, CD34-PE and CD31-FITC. After incubation in the dark for 30 minutes cells were analyzed by Flow Cytometer (Beckman Coulter flow cytometer, USA).

\section{Endothelial differentiation:}

MSCs were harvested by trypsinization in petri dishes $3 \mathrm{~mm}$. The endothelial differentiation was induced by adding $50 \mathrm{ng} / \mathrm{ml}$ VEGF for 7 days. Medium was changed every 3 days. The dishes were incubated in $37^{\circ} \mathrm{C}$ at $5 \% \mathrm{CO} 2$ incubator. The endothelial cells were evaluated by post induction morphological changes under inverted microscope. The harvested endothelial cells at day 8 were trypsinized and identified by flowcytometric analysis of surface markers CD3-FITC, CD34-PE. The harvested endothelial cells at day 8 were identified by detection of vascular endothelial cadherin (CD144) by immunocytochemistry. The cells were washed twice with warm PBS, cells were fixed with $4 \%$ paraformaldehyde for 15 minutes. Cells were permeated with $1 \%$ Triton X-100 for 10 minutes. Then cells were treated with $1 \%$ fetal bovine serum for 30 minutes to block nonspecific bindings. Cells were then incubated 1 hour with mouse antibodies against vascular endothelial (VE)-cadherin, at room temperature. Cells were washed with PBS and incubated for 1 hour with PEconjugated anti-mouse IgG. And then Cells were observed under a fluorescent microscope.

Growth curve analysis: Proliferation curves were done for non-induced cells, 5 bone marrow samples and 5 umbilical cord samples. MSCs at 10,000 cells were seeded in $60 \mathrm{~mm}$ tissue culture dishes coated with full medium. Every 4 days, the cells were harvested with trypsin/EDTA and counted using a hemocytometer for up to 5 passages. The mean value of the cell number counts was calculated from 10 samples from each cell population and the mean population doubling time was obtained for each passage according to the following formula: population doubling time $=\mathrm{T} \times \lg 2 /(\operatorname{lgNt}-\operatorname{lgN} 0)$, where $\mathrm{T}$ is the culture time, $\mathrm{N} 0$ is the initial cell 
number and Nt is the harvested cell number (Roth V. Available from 2006 at: http://www.doublingtime.com/compute.php ).

Statistical analysis: Analysis was performed using IBM SPSS Statistics version 20. Data was expressed into descriptive which include mean value, and standard Deviation (SD). Analytic which include Student's t-test and the Mann-Whitney test, Wilcoxon signed ranked test and F test (one way a nova test).

\section{Morphological identification of MSCs:}

\section{Results}

From bone marrow: $15 / 20$ cases of bone marrow were successfully isolated, 5 cases had failed due to contamination of culture. The onset of fibroblast like cell formation could be observed approximately at day $3 \&$ 4; BM-MSCs grew as a monolayer of large, flat cells. At day7, cells showed multi-polar fibroblastoid cells and a $60 \%$ confluence, which gradually increased to reach $80 \%$ - 90\% confluence at about 9 days (Fig.1). From Umbilical cord Wharton's jelly: Attached cells were observed at 5-7 days after the initial plating. These cells then gradually reached 50\% - 60\% confluency at about 14 days (Fig.2).

\section{Identification of MSCs by flowcytometry:}

MSCs showed positive expression for CD44 81.2 \pm 12.4 for BM and 77.1 \pm 12.7 for UC. MSCs showed negative expression for CD34 1.97 \pm 1.5 for BM and 1.7 \pm 1 for UC. MSCs showed negative expression for CD31 $2.4 \pm 1.8$ for $\mathrm{BM}$ and $1.99 \pm 1.6$ for UC. No significant statistical difference ( $\mathrm{P}$ value $>0.05$ ) was found between MSCs of BM and UC as regard CD expression (Table 1).

Morphological changes of differentiated endothelial cells: MSCs induced with VEGF show spindle shape with no much morphology difference form MSCs (Fig. 3).

\section{Flow cytometric analysis of induced cells:}

Induced MSCs showed positive expression of CD31 $74.2 \pm 12$ for BM and $87.9 \pm 4.5$ for UC. They showed positive expression of CD34 $83.4 \pm 10.4$ for BM and $83.7 \pm 9.3$ for UC. There was highly significant statistical difference $(\mathrm{P}<0.001)$ between induced and non-induced MSCs as regard CD31, CD34 expressions (Table 2). Induced MSCs showed positive double expression of CD31 and CD34 67.03 \pm 8.1 for BM and of $61.9 \pm 6.4$ for UC. There was no significant statistical difference $(\mathrm{P}>0.05)$ between induced BM- MSCs and UCMSCs as regard \% of double expression of CD31 and CD34.

Detection of vascular endothelial cadherin (CD144) by immunocytochemical analysis: The cells were positive for immunostaning in which cell characteristic appear clearly with no difference between BM-MSCs and UC-MSCs (Fig. 4).

Hematoxylin and Eosin Staining: The endothelial cells appear typically spindle shape with pink cytoplasm and blue nucleus (Fig. 5).

\section{Proliferation Potential of Bone of MSCs}

During cells proliferation, MSCs were cultured up to passage 5. The UC-MSCs displayed the highest cumulative cell population followed by BM-MSCs. Based on the cell doubling time calculation, the mean cell doubling time of the BM-MSCs was approximately $99.5 \pm 2.9$ hours, and that of the UC-MSCs was approximately $74.5 \pm 10.9$ hours (Fig 6). There was statistic difference between BM and UCJ as regarded doubling time ( $\mathrm{p}$ value 0.004 ) (Table 3 ).

Table (1): Statistical analysis of flow cytometric results CD34, CD44, CD 31 (\%) on MSCs.

\begin{tabular}{|l|l|l|l|l|}
\hline & BM-MSCs & UC-MSCs & Mann Whitney U test & P value \\
\hline CD44 & & & & \\
Mean \pm SD & $81.2 \pm 12.4$ & $77.1 \pm 12.7$ & & \\
Median & 82.1 & 72.8 & 0.665 & 0.514 \\
Range & $60.7-96.2$ & $63.9-93.1$ & & \\
\hline CD34 & & & & \\
Mean \pm SD & $1.97 \pm 1.5$ & $1.7 \pm 1$ & 0.393 & \\
Median & 1.24 & 1.5 & & \\
Range & $0.35-5.07$ & $0.65-3.5$ & & \\
\hline CD31 & & $1.99 \pm 1.6$ & & 0.663 \\
Mean \pm SD & $2.4 \pm 1.8$ & 1.22 & 0.443 & \\
Median & 1.52 & $0.89-4.84$ & & \\
Range & $0.64-6.25$ & & & \\
\hline
\end{tabular}

SD: stander deviation

$P$ value of $>0.05$ was considered statistically non-significant. 
Isolation Of Mesenchymal Stem Cells From Wharton's Jelly In Comparison With Bone Marrow...

Table (2): Statistical comparison of Mesenchymal stem cells and induced cells as regarde CD 31, CD 34 expression.

\begin{tabular}{|l|l|l|l|l|}
\hline & Non induced & Induced & Wilcoxon signed ranked test & P value \\
\hline CD 31 BM & & & & \\
Mean \pm SD & $2.4 \pm 1.8$ & $74.2 \pm 12$ & & \\
Median & 1.52 & 74.9 & 23.1 & $<0.001$ \\
Range & $0.64-6.25$ & $52.4-91.2$ & & \\
\hline CD31 UC & & & & \\
Mean \pm SD & $1.99 \pm 1.6$ & $87.9 \pm 4.5$ & & \\
Median & 1.22 & 87.45 & 46.9 & \\
Range & $0.89-4.84$ & $82.2-94.4$ & & \\
\hline T test & 0.443 & 2.7 & & \\
\hline P value & 0.663 & 0.015 & & \\
\hline CD 34 BM & & & & \\
Mean \pm SD & $1.97 \pm 1.5$ & $83.4 \pm 10.4$ & & \\
Median & 1.24 & 87 & 31.1 & \\
Range & $0.35-5.07$ & $64.9-95.2$ & & \\
\hline CD 34 UC & & & & \\
Mean \pm SD & $1.7 \pm 1$ & $83.7 \pm 9.3$ & & \\
Median & 1.56 & 86.75 & 22.2 & \\
Range & $0.65-3.5$ & $68.7-94.9$ & & \\
\hline T test & 0.393 & 0.06 & & \\
\hline P value & 0.699 & 0.952 & & \\
\hline
\end{tabular}

$P$ value of $<0.05$ was considered statistically significant

T test: Student's t-test

Table (3): Comparison between BM-MSCs and UC-MSCs groups regarding doubling time

\begin{tabular}{|c|c|c|c|c|}
\hline Doubling time /hours Passage & BM-MSCs $\quad \mathrm{N}=6$ & UC-MSCs $\quad \mathrm{N}=6$ & t test & P value \\
\hline $\begin{array}{l}\text { P1 } \\
\text { Mean } \pm \text { SD } \\
\text { Median } \\
\text { Range }\end{array}$ & 0 & 0 & -- & -- \\
\hline $\begin{array}{l}\text { P2 } \\
\text { Mean } \pm \text { SD } \\
\text { Median } \\
\text { Range }\end{array}$ & $\begin{array}{l}99.2 \pm 26.5 \\
96.5 \\
67-142\end{array}$ & $\begin{array}{l}58.5 \pm 8.6 \\
59 \\
47-70\end{array}$ & 3.6 & 0.005 \\
\hline $\begin{array}{l}\text { P3 } \\
\text { Mean } \pm \text { SD } \\
\text { Median } \\
\text { Range }\end{array}$ & $\begin{array}{l}101.8 \pm 13 \\
102 \\
84-121 \\
\end{array}$ & $\begin{array}{l}73 \pm 7.4 \\
71 \\
65-84\end{array}$ & 4.7 & 0.001 \\
\hline $\begin{array}{l}\text { P4 } \\
\text { Mean } \pm \text { SD } \\
\text { Median } \\
\text { Range }\end{array}$ & $\begin{array}{l}99 \pm 6.4 \\
94.5 \\
88-107\end{array}$ & $\begin{array}{l}80.2 \pm 5.1 \\
78.5 \\
75-87\end{array}$ & 5.6 & $<0.001$ \\
\hline $\begin{array}{l}\text { P5 } \\
\text { Mean } \pm \text { SD } \\
\text { Median } \\
\text { Range }\end{array}$ & $\begin{array}{l}97.8 \pm 4.6 \\
98 \\
93-105\end{array}$ & $\begin{array}{l}83.5 \pm 4.4 \\
82.5 \\
79-91\end{array}$ & 5.5 & $<0.001$ \\
\hline F test & 0.07 & 2.9 & -- & -- \\
\hline P value & 0.741 & 0.06 & -- & -- \\
\hline Doubling time/ hours & $99.5 \pm 2.9$ & $74.2 \pm 10.9$ & 4.4 & 0.004 \\
\hline
\end{tabular}

$P$ value of $<0.05$ was considered statistically significant.

T test: Student's t-test.

F test: one way a nova test.

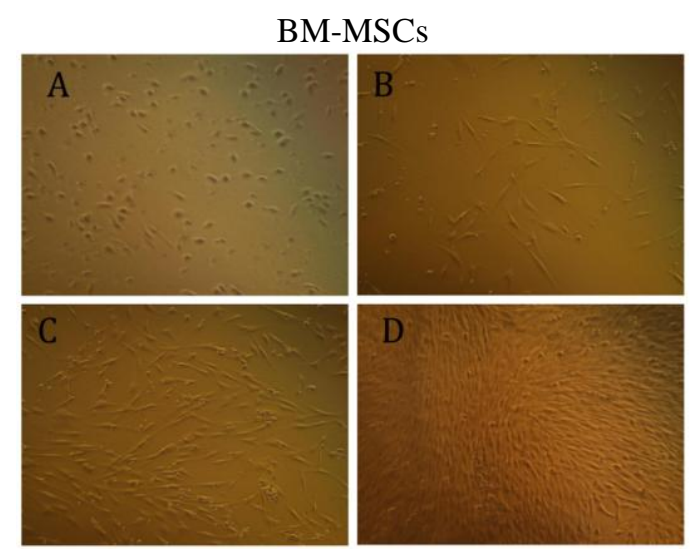


Fig. (1): Inverted microscope image of BM-MSCs (A): Day 3, Cells tend to coalesces and form projections, some fibroblasts-like cells are already formed, with floating non adherent cells. (B): Day 5 Adherent MSCs with floating non adherent cells, some cells had formed fibroblasts-like cells. (C): Day 7, Adherent MSCs after removal of floating non-adherent cells, colony forming unit-fibroblasts like cells were seen. (D): Day 9: Adherent MSCs after removal of floating non adherent cells, it showed $80-90 \%$ fibroblasts like cells confluence.

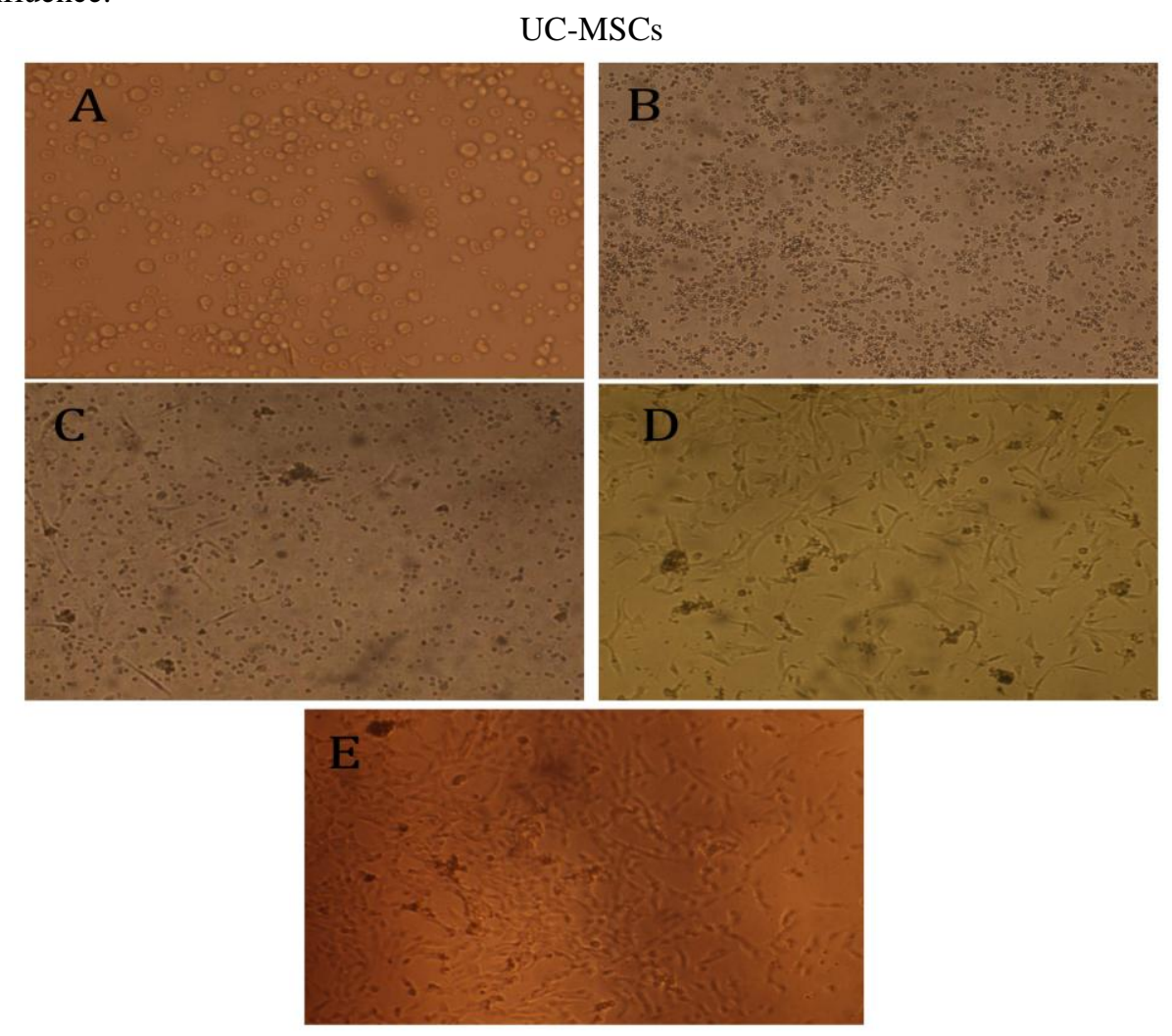

Figure (2): Inverted microscope image of UC-MSCs (A): Day 3, rounded cells floating in the media after 1st seeding. (B): Day 7, discrete adherent cell layer with heterogeneous morphology (round and epithelioid cells) at the base of the flasks, and other cells floated in the media. (C): Day 10, adherent MSCs with floating non adherent cells. (D): Day 13 adherent fibroblast-like cells grew as spindle shaped cells at 50\% - 60\% confluence. (E): adherent fibroblast-like cells grew as spindle shaped cells at $60 \%-70 \%$ confluence.

After differention

BM Endothelia differentiated MSCs

UC Endothelia differentiated MSCs
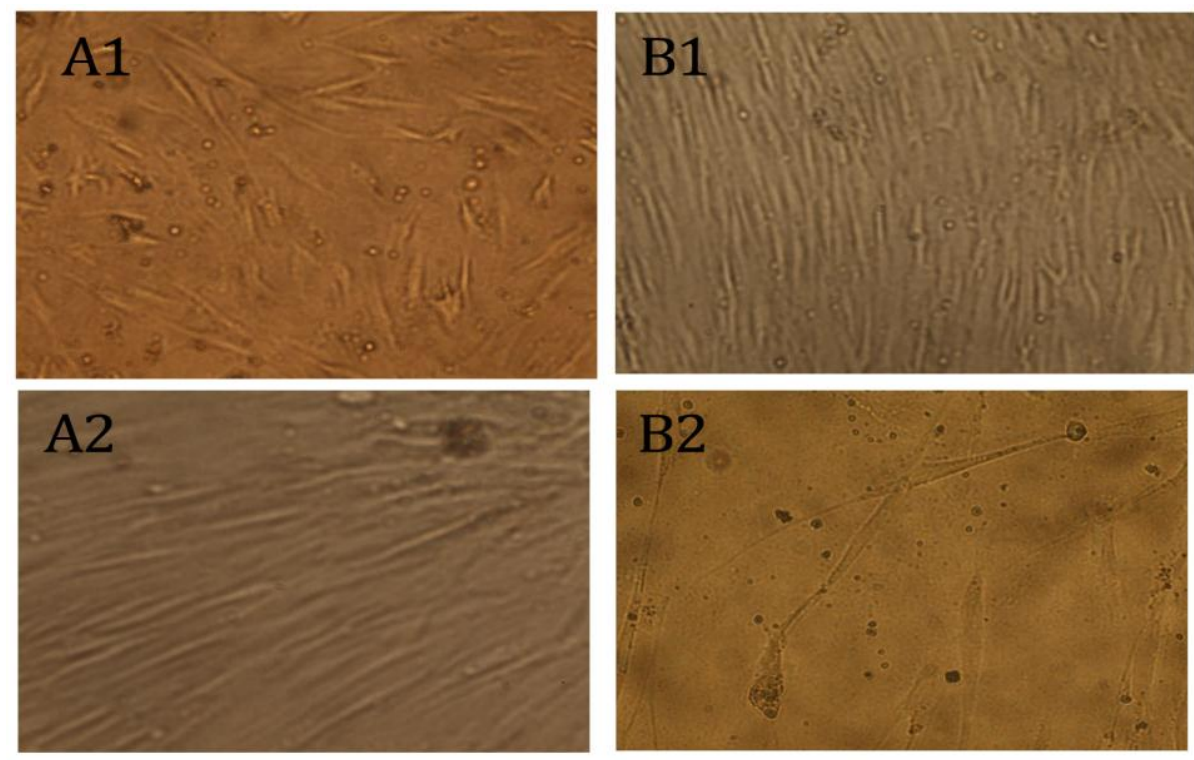
Fig. (3): Endothelia differention of MSCs by VEGF. Inverted microscope image x200 of BM Endothelia differentiated MSCs day 3 (A1), day 7 (A2). Inverted microscope image x200 of UC Endothelia differentiated MSCs day 3 (B1), day 7 (B2). Inverted microscope image x400 of UC Endothelia differentiated MSCs day 7.

VE-cadherin detection by immunocytochemistry
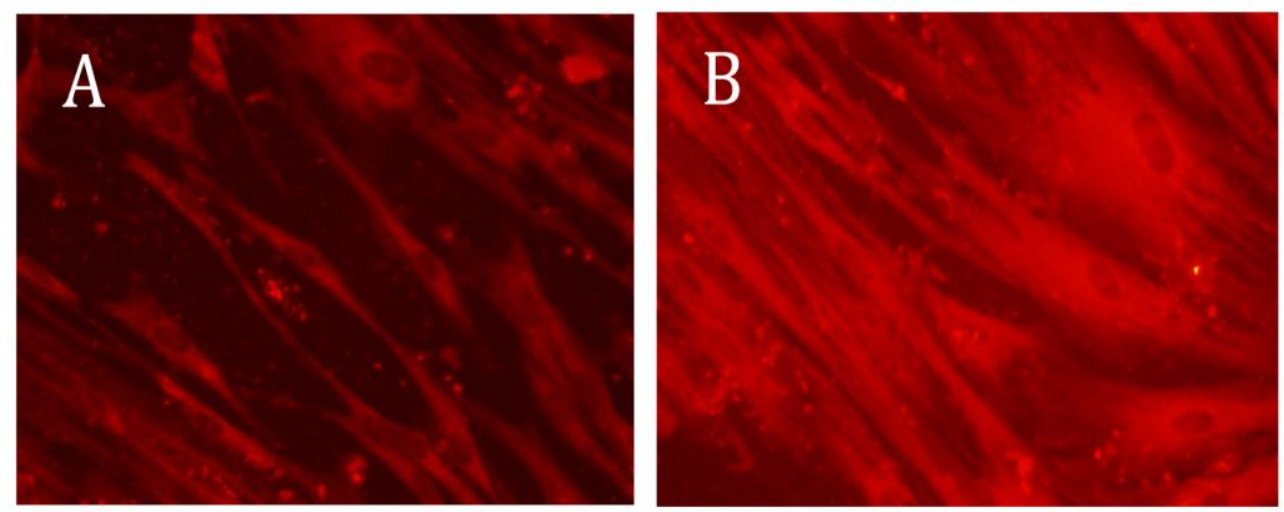

Fig. (4): Microscopic image of immunocytochemistry staining of endothelial cells with VE-cadherin x 200 ( A), x 400 (B)

Hematoxin \& Eosin staining of endothelial cells

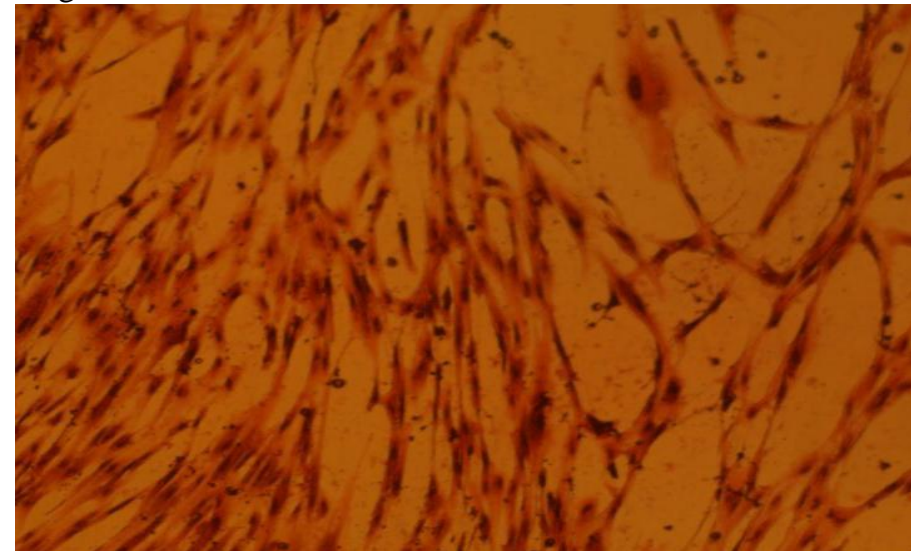

Fig. (5): Inverted microscope image x100 of endothelial cells stained with Hematoxin \& Eosin.

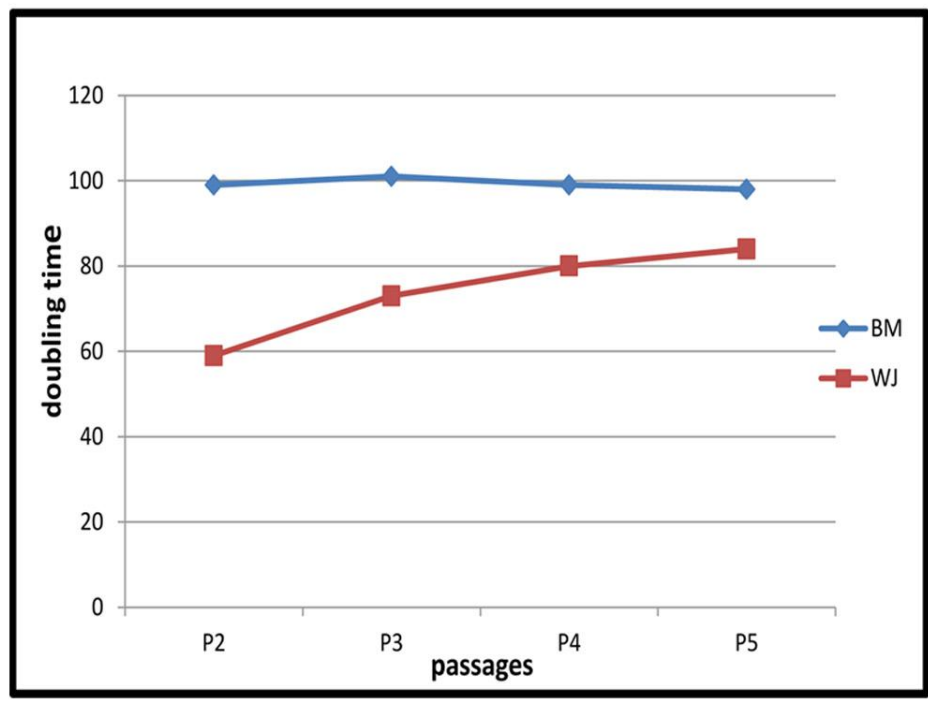

Fig. (6): The population doubling time. BM: bone marrow mesenchymal stem cells, WJ: Umbilical cord mesenchymal stem cells. 


\section{Discussion}

In this study, 20 bone marrow samples and 10 umbilical cord samples were used for isolation of MSCs and induction of their differentiation to endothelial cells. MSCs were isolated from 75\% BM (15/20) samples and 5 samples were failed due to contamination. Culture of BM-MSCs was done on DMEM supplemented with fetal bovine serum (FBS) that was in agreement with Feng et al., and Ayatollahi et al. [11 -12].We used low glucose DMEM and this was associated with good isolation of MSCs. This result was consistent with Ayatollahi et al., and Deorosan and Nauman [12 -13]. At day 7, cells showed multi-polar fibroblastoid cells and a $60 \%$ confluence which gradually increased to reach $80 \%-90 \%$ confluence at about 9 days. This result was agreed with Pal et al., and Siddiqui [14 -15]. However, Polisetti et al., reported that the spindle shaped cells were appeared on the 2nd day; colonies appeared on 4th day and reached confluence day 10 [16]. Flow cytometric analysis of BM-MSCs showed that these cells were positive for human MSCs marker CD44 $(81.2 \pm 12.4)$, negative for hematopoietic cell markers CD34 (1.97 \pm 1.5$)$ indicating that these cells were not of haematopoietic origin and negative for endothelial marker CD31 (2.4 \pm 1.8$)$.These results agreed with those of Siddiqui, [15], Oh et al., [17]. BM-MSCs are a population of undifferentiated multipotent mesenchymal stromal cells which express HLA class I and do not express HLA class II [18]. Ten umbilical cord samples were used in order to isolate MSCs and to obtain cord blood serum to replace FBS. The success rate in isolating and culturing of MSCs were $60 \%$ (6/10). Failure was due to contamination and use of FBS. The explant method that we used was in agreement with Majore et al., [19]. This procedure is simple, reproducible and yields immunophenotypically homogenous cell population without enzymatic digestion of UC tissue.

In this study, we first used FBS in culturing UC-MSCs and we have noticed that the cells were dyeing within the first week, even without contamination. So, later in the study, we used human cord blood serum (CBS) and it gave better isolation results, as it is rich in growth factors needed for the cells and free of zoonotic pathogens and proteins. This was in agreement with Shetty et al., who reported that the use of CBS solves the issue of infusion of xenogeneic sera into humans with a unique solution that will be of utmost importance in the field of regenerative medicine [20].

UC-MSCs cell exhibit fibroblast-like morphology after seven days. These cells gradually reached $50 \%-$ $60 \%$ confluence at about 14 days. This result agreed with Koliakos et al., [21] and Nagamura- Inoue and He, [22]. The flow cytometric analysis of UC-MSCs showed that these cells were positive for human MSCs marker CD44 (77.1 \pm 12.7$)$ which is specific for cells of the mesenchymal lineage, and negative for hematopoietic cell markers CD34 (1.7 \pm 1$)$ indicating that these cells were not of haematopoietic origin and negative for endothelial marker CD31 (1.99 \pm 1.6$)$. This result agreed with Nagamura- Inoue and He [22], and Kim et al., [23]. There is no statistical difference between UC-MSCs and BM-MSCs in morphology of MSCs and flow cytometric analysis. These results were in agreement with Li et al., [24] and Sabapathy et al., [25].

Based on the cell doubling time calculation, the mean cell doubling time of the BM-MSCs was 99.5 \pm 2.9 hours, and that of the UC-MSCs was $74.5 \pm 10.9$ hours; with a statistically difference between them ( $\mathrm{p}=$ 0.004). The doubling times among the 5 passages of BM and 5 passage of UC did not differ significantly ( value $>0.05$ ). Thus, UC-MSCs showed higher growth rate than BM-MSCs. These results were in agreement with $\mathrm{Li}$ et al., [24]. The differences between adult-derived MSCs and UC-MSCs are that UC-MSCs have the potential for faster expansion ex vivo, and UC-MSCs have telomerase activity and the umbilical cord is relatively enriched for CFU-F compared with bone marrow [26].

MSCs induced with VEGF show spindle shape with no much morphology difference form MSCs and this result agree with Siddiqui, [15]. In this study endothelial cells showed positive expression of CD31 for BM (74.2 \pm 12$)$ and for UC $(87.9 \pm 4.5)$, positive expression of CD34 for BM $(83.4 \pm 10.4)$ and for UC $(83.7 \pm 9.3)$ and positive double expression of CD31 and CD34 for BM $(67.03 \pm 8.1 \%)$ and for UC $(61.9 \pm 6.4 \%)$. These results were agreed with Erdbruegger et al., [27] and Melero-Martin et al., [28]. Shantsila et al., revealed that; endothelial cells continue to mature (7-14 day) and integrate into the endothelium show homogenous morphology, express CD34, CD31 increases with high in vivo angiogenic effect [29]. The cells were positive for immunostaning in which cell characteristic appear clearly with no difference between BM-MSCs and UCMSCs. This is consistent with Chena et al., [30]. As VE-cadherin played an important role in the endothelium maturation during angiogenesis process, and was necessary for vasculargenesis and the repair of damaged vascular diseases. Also, Shamosi et al., reported that; differentiated cells revealed morphology of endothelial cells and expressed CD31/PECAM, VE-cadherin [31]. Siddiqui used laser-scanning cytometry as an alternative method to flow cytometry, MSCs showed expression of VE-cadherin and VCAM-1. These data show increase of expression of endothelial specific marker molecules on MSCs after differentiation with VEGF.

\section{Conclusion}

It could be concluded that MSCs can be successfully isolated from bone marrow and umbilical cord tissue. MSCs isolated from the bone marrow is still considered as the gold standard for MSC applications however, BM has several limitations including MSC low frequency, painful isolation procedure and the decline 
in MSC characteristics with donor's age. WJ is an alternative source of MSCs without ethical concerns from a tissue which is discarded after birth. The WJ-MSCs displayed higher cumulative cell population and shorter doubling time than BM-MSCs. MSCs can differentiate into endothelial cells under the effect of vascular endothelial growth factors giving a chance for new viewpoint for cell-starting point treatment.

\section{References}

[1]. Phinney DG. Building a consensus regarding the nature and origin of mesenchymal stem cells. J Cell Biochem 2002; 38(suppl):712.

[2]. Pittenger MF, Mackay AM, Beck SC, Jaiswal RK, Douglas R, Mosca JD, et al. Multilineage potential of adult human mesenchymal stem cells. Science $1999 ; 284: 143-147$.

[3]. Seo MJ, Suh SY, Bae YC, Jung JS. Differentiation of human adipose stromal cells into hepatic lineage in vitro and in vivo. Biochem Biophys Res Commun 2005; 328:258-264.

[4]. Kim S, Recum HV. Endothelial Stem Cells and Precursors for Tissue Engineering: Cell Source, Differentiation, Selection, and Application Tissue Engineering Part B: Reviews 2008; 14(1): 133-147.

[5]. Pati S, Gerber MH, Menge TD, Wataha KA, Zhao Y. Bone Marrow Derived Mesenchymal Stem Cells Inhibit Inflammation and Preserve Vascular Endothelial Integrity in the Lungs after Hemorrhagic shock. PLoS ONE 2011; 6(9): 10.1371-1884.

[6]. Oswald J, Boxberger S, Jørgensen B, Feldmann S, Ehninger G, Bornhäuser M, et al. Mesenchymal stem cells can be differentiated into endothelial cells in vitro. Stem Cells. 2004; 22:377-384.

[7]. Zhang H, Fazel S, Tian H, Mickle DA, Weisel RD, Fujii T, et al. Increasing donor age adversely impacts beneficial effects of bone marrow but not smooth muscle myocardial cell therapy. Am J Physiol Heart Circ Physiol 2005; 289:H2089-H2096.

[8]. Wang HS, Hung SC, Peng ST, Huang CC, Wei HM, Guo YJ, et al. Mesenchymal stem cells in the Wharton's jelly of the human umbilical cord. Stem Cells 2004; 22:1330-1337.

[9]. Weiss ML, Medicetty S, Bledsoe AR, Rachakatla RS, Choi M, Merchav S, et al. Human umbilical cord matrix stem cells: preliminary characterization and characterization and effect of transplantation in a rodent model of Parkinson's disease. Stem Cells 2006; 24:781-792.

[10]. Fong CY, Chak LL, Biswas A, Tan JH, Gauthaman K, Chan WK et al. Human Wharton's jelly stem cells have unique transcriptome profiles compared to human embryonic stem cells and other mesenchymal stem cells. Stem Cell Reviews and Reports 2011; 7 (1): 1-16.

[11]. Feng Z, Li C, Jiao S, Hu B, Zhao L, In Vitro Differentiation of Rat Bone Marrow Mesenchymal Stem Cells into Hepatocytes. Hepato-Gastroenterology 2011; 58(112): 2081-2086.

[12]. Ayatollahi M, Salmani M, Geramizadeh B, Tabei SZ, Soleimani M, Sanati MH. Conditions to improve expansion of human mesenchymal stem cells based on rat samples. World J Stem Cells 2012; 26; 4(1): 1-8.

[13]. Deorosan B, Nauman E. The role of glucose, serum, and threedimensional cell culture on the metabolism of bone marrow-derived mesenchymal stem cells. Dev Cell 2011; 16:209-221.

[14]. Pal R, Hanwate M, Jan M, Totey S. Phenotypic and functional comparison of optimum culture conditions for up scaling of bone marrow-derived mesenchymal stem cells. J Tissue Eng Regen Med 2009; 3: 163-174.

[15]. Siddiqui IA. In vitro differentiation of mesenchymal stem cells into endothelial cells. Der Pharmacia Sinica 2013; 4(1):106-112.

[16]. Polisetti N, Chaitany V, Babu P Geeta K. Isolation, characterization and differentiation potential of rat bone marrow stromal cells. Neurol India 2010; 58(2): 201-208.

[17]. Oh W, Kim D, Yang YS Lee JK. Immunological properties of umbilical cord blood-derived mesenchymal stromal cells. Cellular Immunology 2008; 251:116-23.

[18]. McGuirk JP, Smith JP, Divine CL, Zuniga M Weiss ML. Wharton's Jelly-Derived Mesenchymal Stromal Cells as a Promising Cellular. Therapeutic Strategy for the Management of Graft-versus-Host Disease. Pharmaceuticals 2015; 8:196-220.

[19]. Majore I, Moretti P, Stahl F, Hass R Kasper C. Growth and Differentiation Properties of Mesenchymal Stromal Cell Populations Derived from Whole Human Umbilical Cord. Stem Cell Rev and Rep 2011; 7: 17-31.

[20]. Shetty P, Bharucha K Tanavde V. Human umbilical cord blood serum can replace fetal bovine serum in the culture of mesenchymal stem cells. Cell Biology International 2007; 31:293e-298.

[21]. Koliakos I, Tsagias N Karagiannis V. Mesenchymal cells isolation from Wharton's jelly, in perspective to clinical applications. Journal of Biological Research-Thessaloniki 2011; 16: 194 - 201.

[22]. Nagamura-Inoue T, He H. Umbilical cord-derived mesenchymal stem cells: Their advantages and potential clinical utility. World J Stem Cells 2014; 26; 6(2): 195-202.

[23]. Kim N, Cho SG. Clinical applications of mesenchymal stem cells. Korean J Intern Med 2013; 28(4):387-402

[24]. Li X, Bai J, Ji X, Li R, Xuan Y, Wang Y. Comprehensive characterization of four different populations of human mesenchymal stem cells as regards their immune properties, proliferation and differentiation. International Journal Of Molecular Medicine 2014; 34(3): 695-704.

[25]. Sabapathy V, Sundaram B, Mankuzhy P, Mankuzhy P, Kumar S. Human Wharton's Jelly Mesenchymal Stem Cells Plasticity Augments Scar-Free Skin Wound Healing with Hair Growth. PLoS ONE 2014; 9(4): e93726.

[26]. Weiss ML, Anderson C, Smedicetty S, Seshareddy KB, Weiss RJ, VanderWerff I, et al. Immune Properties of Human Umbilical Cord Wharton's Jelly-Derived Cells. Stem Cells 2008; 26:2865-2874.

[27]. Erdbruegger U, Haubitz M, Woywodt A. Circulating endothelial cells: A novel marker of endothelial damage .Clinica Chimica Acta 2006; 373(1-2):17-26.

[28]. Melero-Martin JM, Khan ZA, Picard A, Wu X, Paruchuri S, Bischoff J. progenitor cells In vivo vasculogenic potential of human bloodderived endothelial. Blood 2007; 109 (11): 4761-4768.

[29]. Shantsila E, Watson T, Tse H, Gregory YH. New Insights on Endothelial Progenitor Cell Subpopulations and Their Angiogenic Properties. Journal of the American College of Cardiology 2008; 51 (6): 669-71.

[30]. Chena M, Liea P, Lib Z, Weia X. Endothelial differentiation of Wharton's jelly-derived mesenchymal stem cells in comparison with bone marrow-derived mesenchymal stem cells. Experimental Hematology 2009; 37: 629-640.

[31]. Shamosi A, Mehrabani D, Azami M, Ebrahimi-Barough S, Siavashiet V, Ghanbari H, et al. Differentiation of human endometrial stem cells into endotheliallike cells on gelatin/chitosan/ bioglass Nano fibrous scaffolds. Artif Cells Nanomed Biotechnol 2016 16: $1-11$. 